\title{
Satisfaction of Dental Students, Faculty, and Patients with Tooth Shade-Matching Using a Spectrophotometer
}

\author{
Erin Ballard, MS; Michael J. Metz, DMD, MSD, MS; Bryan T. Harris, DMD; Cynthia J. \\ Metz, PhD; Jang-Ching Chou, DDS, MS; Dean Morton, BDS, MS; Wei-Shao Lin, DDS
}

Abstract: The aims of this study were to evaluate dental students' clinical shade-matching outcomes (from subjective use of shade guide) with an objective electronic shade-matching tool (spectrophotometer); to assess patients', students', and supervising faculty members' satisfaction with the clinical shade-matching outcomes; and to assess clinicians' support for use of the spectrophotometer to improve esthetic outcomes. A total of 103 volunteer groups, each consisting of patient, dental student, and supervising faculty member at the University of Louisville, were recruited to participate in the study in 2015 . Using the spectrophotometer, clinical shade-matching outcome $\left(\Delta \mathrm{E}_{\text {clinical }}\right)$ and laboratory shade-matching outcome $\left(\Delta \mathrm{E}_{\text {laboratory }}\right)$ were calculated. Two five-point survey items were used to assess the groups' satisfaction with the clinical shade-matching outcome and support for an objective electronic shade-matching tool in the student clinic. The results showed that both $\Delta \mathrm{E}_{\text {clinical }}(6.5 \pm 2.4)$ and $\Delta \mathrm{E}_{\text {laboratory }}(4.3 \pm 2.0)$ were outside the clinical acceptability threshold $\Delta \mathrm{E}$ values of 2.7 , when visual shade-matching method (subjective usage of shade guide) was used to fabricate definitive restorations. Characteristics of the patients, dental students, supervising faculty members, and restorations had minimal to no effect on the $\Delta \mathrm{E}_{\text {clinical }}$. The patients, dental students, and supervising faculty members generally had positive opinions about the clinical shade-matching outcome, despite the increased $\Delta \mathrm{E}_{\text {clinical }}$ observed. Overall, clinical shadematching outcomes in this school need further improvement, but the patients' positive opinions may indicate the need to revisit the acceptability threshold $\Delta \mathrm{E}$ value of 2.7 in the academic setting.

Ms. Ballard is a DMD student, University of Louisville School of Dentistry; Dr. Michael Metz is Associate Professor and Chair, Department of General Dentistry and Oral Medicine, University of Louisville School of Dentistry; Dr. Harris is Associate Professor and Director of Advanced Education Programs in Prosthodontics, Division of Prosthodontics, Department of Oral Health and Rehabilitation, University of Louisville School of Dentistry; Dr. Cynthia Metz is Assistant Professor, Department of Physiology, University of Louisville School of Medicine; Dr. Chou is Assistant Professor, Division of Prosthodontics, Department of Oral Health and Rehabilitation, School of Dentistry, University of Louisville; Dr. Morton is Professor and Chair, Department of Prosthodontics, Indiana University School of Dentistry; and Dr. Lin is Associate Professor and Director, Division of Prosthodontics, Department of Oral Health and Rehabilitation, School of Dentistry, University of Louisville. Direct correspondence to Dr. Wei-Shao Lin, School of Dentistry, University of Louisville, 501 South Preston Street, Louisville, KY 40292 ; WeiShao.Lin@Louisville.edu.

Keywords: dental education, dental school clinic, clinical education, prosthodontics, dental technology, dental prosthesis coloring

Submitted for publication 9/2/16; accepted 11/23/16

doi: 10.21815/JDE.016.022

$\mathrm{T}$ The shade guide commonly used to visualize the desired shade of dental restorations and communicate the results to the dental laboratory collects the shade-matching result by visual and subjective means..$^{1-5}$ The shade guide is usually designed according to the theory of Munsell's color parameters (hue, value, and chroma), but the use of these parameters varies among commercial systems. ${ }^{6-8}$ Shade guides may differ from each other on which of the three parameters should be matched first and in what order. ${ }^{2,7}$ Among commercially available products, the Vita 3D and the Vita Classical Shade Guides are most commonly used., , $^{-11}$

The subjective nature of the shade guide may allow environmental variants to affect shadematching outcomes. The shade tabs in the guide ap- pear differently under changing lighting conditions (fluorescent, incandescent, or daylight). Metamerism causes an initially pleasing shade match to look like a mismatch in different lighting. ${ }^{1}$ A range of other factors beyond lighting can also affect shade-matching outcomes: for instance, tooth dehydration as result of prolonged procedure ${ }^{12}$ and color alternations of shade tabs after chemical disinfection. ${ }^{13-15}$ The clinician's age ${ }^{16}$ clinical experience, ${ }^{17-20}$ and training ${ }^{21}$ have also been found to influence the accuracy of the shadematching selection. Although color blindness can be a factor, its influence may not be significant. ${ }^{22}$ In an academic institution, the presence of a specialist such as a prosthodontist may also alter a patient's opinion about shade-matching. ${ }^{23}$ Although there are limitations associated with use of a shade guide, it has been 
widely available and accepted by clinicians since the 1950s. ${ }^{1}$ The shade guide is also less expensive than other shade-matching tools, ${ }^{24}$ and many restorative materials have been developed around it. ${ }^{1,25}$ To improve the subjective shade-matching outcomes of the shade guide, researchers recommend using digital photographs to supplement the shade guide-based information, especially for anterior restorations, to provide more detail such as translucence for dental laboratory technicians. ${ }^{26-28}$ Objective dental shade-matching instruments such as the colorimeter, spectroradiometer, and spectrophotometer can also produce useful information. ${ }^{5}$ Through reflection and absorption of light, the spectrophotometer has been found to outperform other electronic shade-matching instruments and the visual shade-matching method..$^{21,29-34}$ Objective dental shade-matching instruments allow for use of an equation established by the International Convention on Illumination as a means to quantify shade-matching communications. ${ }^{1,5}$ The equation is shown as $\Delta \mathrm{E}^{*}=\sqrt{(\Delta \mathrm{L} *)^{2}+(\Delta \mathrm{a} *)^{2}(\Delta \mathrm{b} *)^{2}} .35$ $\Delta \mathrm{E}^{*}$ is the color difference between two objects, $\Delta \mathrm{L}^{*}$ is the difference in lightness-darkness, $\Delta \mathrm{a}^{*}$ is the difference in green-red coordinate, and $\Delta \mathrm{b}^{*}$ is the difference in blue-yellow coordinate. A recent review article summarized the clinical acceptability threshold, indicating a difference in shade that is clinically acceptable..$^{35}$ Although one-third of published studies utilized $\Delta \mathrm{E}^{*}$ of 3.7 as the acceptability threshold, they all referred to the same source from the late 1980s, before the higher esthetic demands of modern dentistry. ${ }^{35,36}$ More recent in vivo studies supported a lowered acceptability threshold at $\Delta \mathrm{E}^{*}$ of $2.7 .33,37$

Visual shade-match selection with a shade guide is subjective and could be affected by many factors. The aims of this study were to evaluate dental students' clinical shade-matching outcomes (from subjective use of shade guide) with an objective electronic shade-matching tool (spectrophotometer); to assess patients', students', and supervising faculty members' satisfaction with the clinical shade-matching outcomes; and to assess clinicians' support for use of the spectrophotometer to improve esthetic outcomes.

\section{Materials and Methods}

Following University of Louisville Institutional Review Board approval (\#14.1182), a convenience sample of 103 volunteer groups of patient, dental student, and supervising faculty member were recruited from the University of Louisville School of Dentistry to participate in the study in 2015 . We sought to evaluate visual shade-matching performance (VITA classical Shade Guide; VITA North America, Yorba Linda, CA, USA) with an objective electronic shadematching tool, the spectrophotometer (Easyshade Advance 4.0; VITA North America). The spectrophotometer was used to assess $\Delta \mathrm{E}^{*}$ in relation to an acceptability threshold (AT) of 2.7.

The volunteer groups received consent forms explaining the benefits, risks, and purpose of the study. Only the patients who fit the following inclusion criteria were recruited. The patient must have received treatment in the form of full coverage, indirect, tooth-colored restorations; have information on the Vita Classic Shade Guide noted in the laboratory authorization form; be able to understand and sign the consent form; and have accepted the functional and esthetic outcomes of the luted restoration with the dental student and supervising faculty member.

Descriptive information such as patients', dental students', and supervising faculty members' gender, specialty, and experience level as well as the restoration location were collected. The laboratory authorization forms were obtained, and the prescription shades (the shade selection the clinician made with the shade guide based on the targeted tooth and communicated to the dental technician for the definitive restoration) were gathered from the laboratory authorizations and noted on the data collection sheet. All the restorations included in this study were fabricated by an outsourced commercial dental laboratory.

Using the spectrophotometer, we recorded the reference shade (the shade of targeted tooth measured by the spectrophotometer, such as adjacent or contralateral tooth, that the clinician intended to match with the shade selection) and the shade of luted definitive restoration (measured by the spectrophotometer intraorally) on the data collection sheet. By using the prescription shade, reference shade, and shade of luted definitive restoration, we calculated two $\Delta \mathrm{E}^{*}$ values with the spectrophotometer. The first value, $\Delta \mathrm{E}_{\text {clinical }}$, measured the difference between the reference shade and the shade of luted definitive restoration. The $\Delta \mathrm{E}_{\text {clinical }}$ represented the clinical objective shade-matching outcome of luted definitive restoration. The second $\Delta \mathrm{E}_{\text {laboratory }}$ reflected the difference between the prescription shade and the shade of luted definitive restoration. The $\Delta \mathrm{E}_{\text {laboratory }}$ represented the ability of the dental technician to provide the desired shade for definitive restorations matched to the information on the laboratory authorization. 
In addition, we asked the participants to respond to two author-designed, survey questions after completing treatment. The first survey item sought to determine participating patients', dental students', and supervising faculty members' satisfaction with the shade-matching outcome. Response options ranged from $1=$ extreme dissatisfaction to $5=$ extreme satisfaction. Patients were given a handheld mirror to view their teeth and luted definitive restoration in the clinic. The second survey item assessed support for an objective electronic shade-matching tool as a way to improve esthetic outcome of the definitive restoration. Response options ranged from $1=$ strong disagreement to $5=$ strong agreement. Neither dental students nor supervising faculty members were shown either $\Delta \mathrm{E}_{\text {laboratory }}$ or $\Delta \mathrm{E}_{\text {clinical }}$ data points; the surveys were based on their visual assessment only. All surveys were administered verbally and privately. In an effort to reduce potential bias associated with the presence of the interviewer in verbal surveys and to standardize the results, questions were asked in the same order each time the surveys were administered. ${ }^{38,39}$

Descriptive statistics were calculated for characteristics of patients, dental students, supervising faculty members, and restorations. Means and standard deviations were calculated for both $\Delta \mathrm{E}_{\text {laboratory }}$ and $\Delta \mathrm{E}_{\text {clinical }}$. The t-test was used to assess whether $\Delta \mathrm{E}_{\text {laboratory }}$ and $\Delta \mathrm{E}_{\text {clinical }}$ and were significantly different from the AT value of 2.7, which was defined to determine clinical acceptance..$^{35}$ The t-test was also used to assess the difference between $\Delta \mathrm{E}_{\text {laboratory }}$ and $\Delta \mathrm{E}_{\text {clinical }}$. The $\mathrm{p}$-values were adjusted for multiple comparisons. Furthermore, means and standard deviations were calculated for $\Delta \mathrm{E}_{\text {laboratory }}$ and $\Delta \mathrm{E}_{\text {clinical }}$ by restoration location (anterior vs. posterior). Linear regression model and Tukey pairwise comparison were used to assess the difference between $\Delta \mathrm{E}_{\text {laboratory }}$ and $\Delta \mathrm{E}_{\text {clinical }}$ by restoration location.

The survey responses were viewed as a continuous measurement scale, and the Pearson product-moment correlation coefficient was tested to investigate potential relationships between $\Delta \mathrm{E}_{\text {clinical }}$ and survey responses. The t-test or one-way ANOVA was used to evaluate the effect of characteristics of patients, dental students, supervising faculty members, and the restorations on $\Delta \mathrm{E}_{\text {clinical }}$. The $\mathrm{p}$-values were adjusted for multiple comparisons. Statistical analysis was performed by a statistician using SAS version 9.4 (SAS Institute, Cary, NC, USA) with statistical significance set at $\mathrm{p}<0.05$.

\section{Results}

In the 103 patient, dental student, and supervising faculty groups, there were more male patients $(56 \%)$ than female (44\%) (Table 1). Dental students were split nearly identically by gender ( $47 \%$ vs. $53 \%$ for males and females, respectively). The dental students were mostly in their fourth year (96\%), and the majority did not have previous experience in clinical dentistry $(73 \%)$. The supervising faculty members were mostly prosthodontists $(78 \%)$.

\section{Table 1. Characteristics of participating patients, dental students, supervising faculty members, and restorations $(\mathrm{N}=103)$}

\begin{tabular}{|c|c|c|}
\hline Characteristic & Number & Percentage \\
\hline \multicolumn{3}{|l|}{ Patients } \\
\hline Male & 58 & $56.3 \%$ \\
\hline Female & 45 & $43.7 \%$ \\
\hline \multicolumn{3}{|l|}{ Dental students } \\
\hline \multicolumn{3}{|l|}{ Gender } \\
\hline Male & 48 & $46.6 \%$ \\
\hline Female & 55 & $53.4 \%$ \\
\hline \multicolumn{3}{|l|}{ Dental background } \\
\hline $\begin{array}{l}\text { No prior experience before } \\
\text { dental school }\end{array}$ & 75 & $72.8 \%$ \\
\hline $\begin{array}{l}\text { Prior experience before dental } \\
\text { school }\end{array}$ & 28 & $27.2 \%$ \\
\hline \multicolumn{3}{|l|}{ Year in dental school } \\
\hline Third & 4 & $3.9 \%$ \\
\hline Fourth & 99 & $96.1 \%$ \\
\hline \multicolumn{3}{|l|}{ Supervising faculty members } \\
\hline General dentists & 23 & $22.3 \%$ \\
\hline Prosthodontists & 80 & $77.7 \%$ \\
\hline \multicolumn{3}{|l|}{ Restorations } \\
\hline \multicolumn{3}{|l|}{ Location } \\
\hline Anterior & 32 & $31.1 \%$ \\
\hline Posterior & 71 & $68.9 \%$ \\
\hline \multicolumn{3}{|l|}{ Supporting structure } \\
\hline Implant & 49 & $47.6 \%$ \\
\hline Natural dentition & 54 & $52.4 \%$ \\
\hline \multicolumn{3}{|l|}{ Type of restoration } \\
\hline Metal-ceramic & 92 & $89.3 \%$ \\
\hline All-ceramic & 11 & $10.7 \%$ \\
\hline \multicolumn{3}{|l|}{ Restorative material } \\
\hline Base-metal alloy & 8 & $7.8 \%$ \\
\hline Noble metal alloy & 83 & $80.6 \%$ \\
\hline High noble metal alloy & 1 & $1.0 \%$ \\
\hline Lithium disilicate & 9 & $8.7 \%$ \\
\hline Zirconia & 2 & $1.9 \%$ \\
\hline
\end{tabular}


Of the 103 definitive restorations, 32 (31\%) were performed on anterior teeth (incisors and canines) (Table 1). The restorations were split 52\% vs. $48 \%$ on natural dentition vs. implant, respectively. While metal-ceramic material was used for the majority of the restorations (89\%), noble metal-alloy was the most common choice of substructure material for the metal-ceramic restorations $(81 \%)$.

$\Delta \mathrm{E}_{\text {clinical }}$ and $\Delta \mathrm{E}_{\text {laboratory }}$ values were normally distributed. Overall $\Delta \mathrm{E}_{\text {clinical }}(6.5 \pm 2.4)$ and $\Delta \mathrm{E}_{\text {labora- }}$ tory $(4.3 \pm 2.0)$ were both significantly higher than the AT $\Delta$ E value of $2.7(p<0.0001)$ (Table 2$)$. The overall $\Delta \mathrm{E}_{\text {clinical }}(6.5 \pm 2.4)$ was significantly higher than the overall mean $\Delta \mathrm{E}_{\text {laboratory }}(4.3 \pm 2.0)(\mathrm{p}<0.001)$. The shade differences $\left(\Delta \mathrm{E}^{*}\right)$ were also analyzed based on the restoration locations (Table 3 ). $\Delta \mathrm{E}_{\text {clinical }}$ and $\Delta \mathrm{E}_{\text {laboratory }}$ in all restoration locations $\left(\Delta \mathrm{E}_{\text {clincal Anterior? }}\right.$, $\Delta \mathrm{E}_{\text {clincal Posterior }}, \Delta \mathrm{E}_{\text {laboratory Anterior' }}$ and $\Delta \mathrm{E}_{\text {laboratory Posterior }}$ ) were significantly higher than the AT $\Delta \mathrm{E}$ value of $2.7(\mathrm{p}<0.0001)$. The difference between $\Delta \mathrm{E}_{\text {clinical }}$ and $\Delta \mathrm{E}_{\text {laboratory }}$ was not evident in the anterior area $\left(\Delta \mathrm{E}_{\text {clincal Anterior }}: 5.6 \pm 2.5\right.$ vs. $\Delta \mathrm{E}_{\text {laboratory Anterior }}: 4.6 \pm 2.0$, $\mathrm{p}=0.08)$. In the posterior area, the difference between $\Delta \mathrm{E}_{\text {clinical }}$ and $\Delta \mathrm{E}_{\text {laboratory }}$ was statistically significant $\left(\Delta \mathrm{E}_{\text {clincal Posterior }}: 6.9 \pm 2.3\right.$ vs. $\Delta \mathrm{E}_{\text {laboratory Posterior }}: 4.2 \pm 1.9$, $\mathrm{p}<0.001)$.

Table 2. Shade differences $\left(\Delta \mathrm{E}^{*}\right)$

\begin{tabular}{lccc} 
& Mean (SD) & p-value & p-value $^{\mathrm{b}}$ \\
\hline$\Delta \mathrm{E}_{\text {clinical }}$ & $6.5(2.4)$ & $<0.0001$ & $<0.001$ \\
$\Delta \mathrm{E}_{\text {laboratory }}$ & $4.3(2.0)$ & $<0.0001$ &
\end{tabular}

a Difference of mean values from 2.7

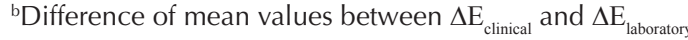

Note: The Bonferroni correction was used to control familywise error rate for multiple comparisons and adjust the $p$ values. All $p$-values were statistically significance at $p \leq 0.05$.
The first survey question was used to assess the participants' satisfaction with the shade-matching outcome (Table 4). Despite the $\Delta \mathrm{E}_{\text {clinical }}$ and $\Delta \mathrm{E}_{\text {laboratory }}$ discrepancies, the majority of the patients $(94.2 \%)$, dental students $(82.5 \%)$, and faculty members $(58.3 \%)$ were satisfied or extremely satisfied. The patients had higher levels of satisfaction than the dental students and faculty members.

The second survey question was used to assess if the supervising faculty members and dental students supported use of an objective electronic shadematching tool as a way to improve esthetic outcome (Table 4). Generally, both the students (77.7\%) and faculty members $(60.2 \%)$ agreed or strongly agreed with its use to improve esthetic outcome. However, the dental students tended to agree more strongly with this statement than the faculty members did.

The effects of characteristics of the patients, dental students, faculty members, and the restorations on the $\Delta \mathrm{E}_{\text {clinical }}$ were also analyzed (Table 5). In general, there were no effects of participants' characteristics on the clinical shade-matching outcome $\left(\Delta \mathrm{E}_{\text {clinical }}\right)$. However, supporting structure (implant vs. natural dentition) $(\mathrm{p}=0.0496)$ had effects on the clinical shade-matching outcome $\left(\Delta \mathrm{E}_{\text {clinical }}\right) . \Delta \mathrm{E}_{\text {clinical }}$ tended to be higher on the implant restorations.

There was no significant correlation between the patients' and students' satisfaction and the clinical shade-matching outcome $\left(\Delta \mathrm{E}_{\text {clinical }}\right)(\mathrm{r}=-0.06, \mathrm{p}=0.55$; $\mathrm{r}=-0.06, \mathrm{p}=0.57$, respectively) (Table 6). There was a significant negative correlation between the supervising faculty members' satisfaction and the clinical shade-matching outcome $\left(\Delta \mathrm{E}_{\text {clinical }}\right)(\mathrm{r}=-0.45$, $\mathrm{p}<0.001)$. The higher the shade difference, the less likely the faculty member was to be satisfied with the matching. Additionally, the faculty member was most likely to agree with use of the objective shadematching equipment if $\Delta \mathrm{E}_{\text {clinical }}$ was high $(\mathrm{r}=0.35$, $\mathrm{p}<0.001$ ).

Table 3. Shade differences $\left(\Delta \mathrm{E}^{*}\right)$ based on restoration location

\begin{tabular}{|c|c|c|c|c|c|c|}
\hline & \multicolumn{3}{|c|}{ Anterior } & \multicolumn{3}{|c|}{ Posterior } \\
\hline & Mean (SD) & $p$-value ${ }^{a}$ & $p$-value ${ }^{b}$ & Mean (SD) & $p$-value ${ }^{a}$ & $p$-value ${ }^{b}$ \\
\hline$\Delta \mathrm{E}_{\text {clinical }}$ & $5.6(2.5)$ & $<0.0001^{*}$ & 0.08 & $6.9(2.3)$ & $<0.0001^{*}$ & $<0.001^{*}$ \\
\hline$\Delta \mathrm{E}_{\text {laboratory }}$ & $4.6(2.0)$ & $<0.0001^{*}$ & & $4.2(1.9)$ & $<0.0001^{*}$ & \\
\hline
\end{tabular}


Table 4. All participants' satisfaction with shade-matching outcome and dental students' and faculty members' support of effectiveness of objective electronic shade-matching tool

\begin{tabular}{|c|c|c|c|}
\hline \multicolumn{2}{|c|}{ Question 1: Satisfaction } & \multicolumn{2}{|c|}{ Question 2: Effectiveness } \\
\hline Patients & Number (Percentage) & & Number (Percentage) \\
\hline Extremely dissatisfied & $1(1.0 \%)$ & & \\
\hline Somewhat dissatisfied & 0 & & \\
\hline Neutral & $5(4.9 \%)$ & & \\
\hline Satisfied & $21(20.4 \%)$ & & \\
\hline Extremely satisfied & $76(73.8 \%)$ & & \\
\hline Median (IQR) & $5(1.0 \%)$ & & \\
\hline Mean (SD) & $4.7(0.7 \%)$ & & \\
\hline Dental students & & Dental students & \\
\hline Extremely dissatisfied & $1(1.0 \%)$ & Strongly disagree & $3(2.9 \%)$ \\
\hline Somewhat dissatisfied & 0 & Disagree & $5(4.9 \%)$ \\
\hline Neutral & $17(16.5 \%)$ & Neutral & $15(14.6 \%)$ \\
\hline Satisfied & $59(57.3 \%)$ & Agree & $32(31.1 \%)$ \\
\hline Extremely satisfied & $26(25.2 \%)$ & Strongly agree & $48(46.6 \%)$ \\
\hline Median (IQR) & $4(1.0 \%)$ & Median (IQR) & $4(1.0 \%)$ \\
\hline Mean (SD) & $4(0.7 \%)$ & Mean (SD) & $4.1(1.0 \%)$ \\
\hline Faculty members & & Faculty members & \\
\hline Extremely dissatisfied & 0 & Strongly disagree & 0 \\
\hline Somewhat dissatisfied & $9(8.7 \%)$ & Disagree & $12(11.7 \%)$ \\
\hline Neutral & $34.0(33.0 \%)$ & Neutral & $29(28.2 \%)$ \\
\hline Satisfied & $45(43.7 \%)$ & Agree & $53(51.5 \%)$ \\
\hline Extremely satisfied & $15(14.6 \%)$ & Strongly agree & $9(8.7 \%)$ \\
\hline Median (IQR) & $4(1.0 \%)$ & Median (IQR) & $4(1.0 \%)$ \\
\hline Mean (SD) & $3.6(0.8 \%)$ & Mean (SD) & $3.6(0.8 \%)$ \\
\hline
\end{tabular}

Note: Question 1 was worded: How satisfied are you with the shade-matching outcome? Question 2 was worded: The use of an electronic objective shade-matching tool may improve the esthetic outcome in this treatment provided to the patient.

\section{Discussion}

Shade-matching with the visual shade guide has previously been found to be subjective, potentially leading to discrepancies in the shade match. ${ }^{1-5,30}$ Our study sought to objectively evaluate the shade-matching outcomes resulting from visual subjective shade selection with a shade guide and to assess patients', dental students', and supervising faculty members' satisfaction with those outcomes and supports for the shade-matching tool.

The mean $\Delta \mathrm{E}_{\text {clinical }}$ in our study was significantly above 2.7 , the acceptability threshold recommended in previous studies. ${ }^{33,35,37}$ The $\Delta \mathrm{E}_{\text {clinical }}$ represented the clinical objective shade-matching outcomes. From clinicians' perspective, the clinical experience has been found to lead to greater shade-matching success. ${ }^{17-20}$ The results of our study could possibly contribute to dental students' lower level of clinical experiences. In addition, Burki et al. found that dental students tended to spend more time in clinical procedures to allow for verification from the supervising faculty, potentially allowing tooth dehydration to lead to differences in color parameters that make up E equation. ${ }^{12}$ Furthermore, Khashayar et al. reported that the majority of studies that contribute to current knowledge of acceptability/perceptibility thresholds were in vitro-based, potentially excluding the clinical environment. ${ }^{35}$ For reasons such as these, in conjunction with the high patient satisfaction ratings, it may be useful to re-evaluate stringent $\mathrm{E}$ thresholds.

In our study, the $\Delta \mathrm{E}_{\text {laboratory }}$ represented the ability of dental technicians to provide the desired shade for definitive restorations matching information on the laboratory authorization, and the mean $\Delta \mathrm{E}_{\text {labora- }}$ tory value was also above the clinical acceptability threshold value of 2.7. ${ }^{33,37}$ The $\Delta \mathrm{E}_{\text {laboratory }}$ value was statistically lower than the $\Delta \mathrm{E}_{\text {clinical }}$ value. This result 
Table 5. Effects of participants' and restorations' characteristics on clinical shade-matching outcome $\left(\Delta \mathrm{E}_{\text {clinical }}\right)$

\begin{tabular}{|c|c|c|c|}
\hline & & $\Delta \mathrm{E}_{\text {clinical }}$ & \\
\hline Characteristic & Estimate & Std Err & p-value \\
\hline \multicolumn{4}{|l|}{ Patients } \\
\hline Gender (male vs. female) ${ }^{\mathrm{a}}$ & 0.07 & 0.48 & 0.88 \\
\hline \multicolumn{4}{|l|}{ Dental students } \\
\hline Gender (male vs. female) ${ }^{\mathrm{a}}$ & -0.32 & 0.47 & 0.50 \\
\hline Dental background (none vs. some) ${ }^{\mathrm{a}}$ & 0.68 & 0.53 & 0.20 \\
\hline Year in dental school (third vs. fourth) ${ }^{a}$ & -2.20 & 1.20 & 0.07 \\
\hline \multicolumn{4}{|l|}{ Supervising faculty members } \\
\hline Prosthodontist vs. general dentist ${ }^{\mathrm{a}}$ & 1.03 & 0.31 & 0.10 \\
\hline \multicolumn{4}{|l|}{ Restorations } \\
\hline Supporting structure (implant vs. natural dentition) ${ }^{a}$ & 0.92 & 0.46 & $0.0496 *$ \\
\hline Types of restoration (metal-ceramic vs. all-ceramic) ${ }^{a}$ & -0.16 & 0.71 & 0.82 \\
\hline Restorative materials ${ }^{\mathrm{b}}$ & & & 0.74 \\
\hline
\end{tabular}

aThe t-test and ' One-way ANOVA were used to evaluate effects of participants' and restorations' characteristics on clinical shade-matching outcome. Restorative materials were base-metal, noble-metal, high noble alloy, lithium disilicate, and zirconia.

*Statistically significant at $\mathrm{p}<0.05$

Table 6. Correlations between clinical shade-matching outcome $\left(\Delta \mathrm{E}_{\text {clinical }}\right)$ and participants' satisfaction with shadematching outcome and support for objective shade-matching tool

\begin{tabular}{lcc}
\multicolumn{1}{c}{$\Delta \mathrm{E}_{\text {clinical }}$} & \\
\hline & Correlation Coefficient $(\mathrm{r})$ & $\mathrm{p}$-value \\
\hline Satisfaction with shade-matching outcome & & 0.55 \\
$\quad$ Patients & -0.06 & 0.57 \\
$\quad$ Dental students & -0.06 & $<0.001^{*}$ \\
$\quad$ Supervising faculty members & -0.45 & 0.27 \\
Support for objective electronic shade-matching tool & 0.11 & $<0.001^{*}$ \\
$\quad$ Dental students & 0.35 & \\
$\quad$ Supervising faculty members & & \\
Note: The Pearson Correlation test was used to test correlation between clinical shade-matching outcome $\left(\Delta \mathrm{E}_{\text {clinical }}\right)$ and survey out- \\
comes.
\end{tabular}

is reasonable, since the $\Delta \mathrm{E}_{\text {clinical }}$ is the combined reflection of the clinician's ability to select the desired shade and the $\Delta \mathrm{E}_{\text {laboratory }}$ dental technician's ability to duplicate laboratory authorization. One noteworthy finding is that most of the laboratory authorizations included in this study did not provide clinical photographs. Previous studies support the use of digital photographs since that additional information is helpful in communicating between the clinician and dental technician. ${ }^{26-28}$ The laboratory authorizations also showed that the majority of these dental students did not include the dentin shade selection for all- ceramic restorations. Without this information, the laboratory may not be able to adequately incorporate the hue of the underlying tooth structure to create an accurate shade-match outcome, thus adversely affecting both $\Delta \mathrm{E}_{\text {clinical }}$ and $\Delta \mathrm{E}_{\text {laboratory }}{ }^{8}$

The functional and esthetic outcomes of the definitive restoration were confirmed by both clinicians and patients as clinically acceptable, indicating some initial level of satisfaction with the shade match. The satisfaction survey showed that $94.2 \%$ of the patients were at least satisfied or extremely satisfied with the clinical shade-matching outcome, 
despite significant $\Delta \mathrm{E}_{\text {clinical }}$ discrepancies. The patients frequently mentioned the desire to whiten their teeth after receiving restorations during this study. Patient satisfaction may have been influenced by the lightness of the restoration shade-whether or not restoration shade and target shade truly matched. In addition, Al-Wahadni et al. found that patients tended to rate restorations more favorably when the restoration was received in an academic institution. ${ }^{23}$ Those researchers noted that the patients' pride in the school or positive relationship with the dental student may have elevated his or her opinion of the care received.

Considering the statistically significant level of discrepancy in $\Delta \mathrm{E}_{\text {clinical }}$, it would be expected that at least the dental students and supervising faculty members would have been able to detect the shade mismatch. However, the majority of dental students $(82.5 \%)$ and supervising faculty members $(58.3 \%)$ reported being at least satisfied or extremely satisfied with the shade-matching outcome. The students' favorable rating may be attributed to lack of experience. ${ }^{16,17,19}$ It is also possible that the students and faculty members tailored the laboratory authorizations to the patients' request for a lighter restoration shade despite the actual shade match, leading to a satisfied patient, therefore satisfied clinicians, but a contradicting shade match with higher $\Delta \mathrm{E}$. While these faculty members were generally satisfied with the shade-matching outcomes (58.3\%), a significant correlation between $\Delta \mathrm{E}_{\text {clinical }}$ and faculty satisfaction was observed. As $\Delta \mathrm{E}_{\text {clinical }}$ decreased, the faculty members were more satisfied. Clinical experience is important to shade-matching accuracy, and it is possible that the faculty members realized that students were not experienced and therefore tolerated some flexibility. ${ }^{16-19,33}$

Despite these satisfaction ratings, both the dental students $(77.7 \%)$ and supervising faculty members $(60.2 \%)$ agreed or strongly agreed with use of an objective electronic shade-matching tool to improve esthetic outcome. Overall, the dental students were generally supportive of the need for an objective electronic shade-matching tool. Dental students may not be confident in their ability, due to their lower level of experience, to perform accurate shade-matching with a shade guide. The idea of removing doubt from subjective selection with an objective electronic tool could be a welcoming concept for students. The supervising faculty members' agreement with the objective electronic shade-matching tool correlated with $\Delta \mathrm{E}_{\text {clinical }}(\mathrm{r}=0.35 ; \mathrm{p}<0.001)$ significantly. The faculty members never saw the actual $\Delta \mathrm{E}_{\text {clinical }}$ value; this correlation came from strictly visual assessment. In other words, the faculty members were more able to discern visual inaccuracies in shade without knowledge of any quantitative markers than the students. Da Silva et al. had similar findings when they created two sets of crowns, evaluated the accuracy of the crowns, and then had experienced faculty members choose the most accurate shade-match through visual mean only ${ }^{33}$ In their study, the experienced clinicians consistently chose the group with the lower $\Delta \mathrm{E}$.

The patients included in our study reported high satisfaction ratings, indicating that subjective visual shade-matching selection with a shade guide can still be a viable option to produce definitive restoration with clinically acceptable esthetic outcome. Previous studies explored issues associated with visual shade matching ${ }^{2,7,11,13-15}$ and the efficacy of the spectrophotometer extensively. ${ }^{16,30-34}$ Our study explored different components of the shade-matching outcome from subjective visual shade-matching selection with a shade guide and can potentially provide future direction of shade-matching education in dental schools.

A limitation of our study was the unknown reliability and validity of the author-developed survey items. Future research should be conducted to confirm the reliability of the survey items and to validate their use. Another limitation of our study is that the objective electronic shade-matching devices can vary in their reliability and accuracy to produce color measurements. Kim-Pusateri et al. found that most devices showed similar high reliability (over $96 \%$ ) but more variability in accuracy among devices $(67-93 \%) .{ }^{34}$ More laboratory and clinical studies should be conducted to investigate the reliability and accuracy of the objective electronic shade-matching devices and to predict their performance in the clinical setting. In future research, study participants can be screened for color blindness or other color vision deficiency to eliminate any potential influence to shade-matching outcome, as called for by $\mathrm{Chu}$ et al. and Poljak-Guberina et al., ${ }^{1,22}$ Further research can also focus on the clinical control trial to revisit clinical acceptability threshold with different patient populations, effect of training programs on the improvement of clinical esthetic outcomes with subjective visual shade-matching method, or cost-benefit analysis of implementation of an objective electronic shade-matching tool with a clinical study. 


\section{Conclusion}

In this study, shade discrepancy outside the clinical acceptability threshold value of 2.7 was noted in both $\Delta \mathrm{E}_{\text {clinical }}$ and $\Delta \mathrm{E}_{\text {laboratory }}$, when subjective visual shade-matching method was used with a shade guide to fabricate definitive restorations. Characteristics of the patients, dental students, supervising faculty members, and the restorations had none to minimal effect on the clinical shade-matching outcome $\left(\Delta \mathrm{E}_{\text {clinical }}\right)$. The majority of patients, dental students, and faculty members reported being satisfied with the shade-match outcome resulting from the subjective visual shade-matching method, despite the increased mean value of 6.5 . The generally accepted clinical acceptability threshold value of 2.7 may need to be revisited based on different patient populations and clinical environments (in vitro vs. clinical; academia vs. private practice). The dental students and faculty members in our study were supportive of objective electronic shade-matching tool as a way to improve shade-matching outcome. $\Delta \mathrm{E}_{\text {clinical }}$ correlated significantly with faculty satisfaction as well as agreement of the need for objective shade measurement, indicating experienced clinicians' higher ability to discern shade discrepancy.

\section{REFERENCES}

1. Chu SJ, Devigus A, Paravina RD, et al. Fundamentals of color: shade matching and communication in esthetic dentistry. $2^{\text {nd }}$ ed. Hanover Park, IL: Quintessence, 2010.

2. Park JH, Lee YK, Lim BS. Influences of illuminants on the color distribution of shade guides. J Prosthet Dent 2006;96(6):402-11.

3. Lee YK, Yu B, Lim JI, Lim HN. Perceived color shift of a shade guide according to the change of illuminant. J Prosthet Dent 2011;105(2):91-9.

4. Bhat V, Prasad DK, Sood S, Bhat A. Role of colors in prosthodontics: application of color science in restorative dentistry. Indian J Dent Res 2011;22(6):804-9.

5. Paravina RD, Powers JM. Esthetic color training in dentistry. St. Louis: Elsevier Mosby, 2004.

6. Fondriest J. Shade matching in restorative dentistry: the science and strategies. Int J Period Restor Dent 2003;23(5):467-79.

7. Ahn JS, Lee YK. Color distribution of a shade guide in the value chroma and hue scale. J Prosthet Dent 2008;100(1):18-28.

8. Chiche GJ, Pinault A. Esthetics of anterior fixed prosthodontics. Chicago: Quintessence, 1994.

9. Paravina RD, O'Neill PN, Swift EJ, et al. Teaching of color in predoctoral and postdoctoral dental education in 2009. J Dent 2010;38(Suppl 2):e34-40.

10. Bartlett, DW, Fisher NF. Clinical problem solving in prosthodontics. Edinburgh: Churchill Livingstone, 2004.
11. Sikri VK. Color implications in dentistry. J Conserv Dent 2010;13(4):249-55.

12. Burki Z, Watkins S, Wilson R, Fenlon M. A randomized controlled trial to investigate the effects of dehydration on tooth color. J Dent 2013;41(3):250-7.

13. Schmeling M, Sartori N, Monteiro S, Baratieri L. Color stability of shade guides after autoclave sterilization. Int J Period Restor Dent 2014;34(5):689-93.

14. ArRejaie AS. The effect of chemical disinfectants on the color of a porcelain shade guide. Int J Health Sci (Qassim) 2014;8(3):299-304.

15. Huang PY, Masri R, Romberg E, Driscoll CF. The effect of various disinfectants on dental shade guides. J Prosthet Dent 2014;112(3):613-7.

16. Dozic A, Kleverlaan CJ, El-Zohairy A, et al. Performance of five commercially available tooth color-measuring devices. J Prosthodont 2007;16(2):93-100.

17. Li Q, Yu H, Wang YN. In vivo spectroradiometric evaluation of color matching errors among five shade guides. J Oral Rehabil 2009;36(1):65-70.

18. Della Bona A, Barrett AA, Rosa V, Pinzetta C. Visual and instrumental agreement in dental shade selection: three distinct observer populations and shade matching protocol. Dent Mater 2009;25(2):276-81.

19. Capa N, Malkondu O, Kazazoglu E, Calikkocaoglu S. Evaluating factors that affect the shade-matching ability of dentists, dental staff members, and laypeople. J Am Dent Assoc 2010;141(1):71-6.

20. Ramesh AS, Sharma A, Rijesh K, et al. Assessment of perceptibility and acceptability of color variations between matched teeth among trainee dentist and lay person. J Pharm Bioallied Sci 2015;7(Suppl 2):S632-5.

21. Al-Dosari AAF. Reliability of tooth shade perception by dental professionals. Pak Oral Dent J 2010;30(1):244-9.

22. Poljak-Guberina R, Celebic A, Powers JM, Paravina RD. Color discrimination of dental professionals and color deficient laypersons. J Dent 2011;39(Suppl 3):e17-22.

23. Al-Wahadni A, Ajlouni R, Al-Omari Q, et al. Shade-match perception of porcelain-fused-to-metal restorations: a comparison between dentist and patient. J Am Dent Assoc 2002;133(9):1220-5.

24. Joiner A. Tooth color: a review of literature. J Dent 2004;32(Suppl 1):3-12.

25. Geissberger M. Esthetic dentistry in clinical practice. Ames, IA: Wiley-Blackwell, 2010.

26. Jarad F, Russell M, Moss B. The use of digital imaging for color matching and communication in restorative dentistry. Br Dent J 2005;199(1):43-9.

27. Derbabian K, Marzola R, Donovan TE, Aricidiacomo A. The science of communicating the art of esthetic dentistry. Part III: precise shade communication. J Esthet Restor Dent 2001;13(3):154-62.

28. Schropp L. Shade matching assisted by digital photography and computer software. J Prosthodont 2009;18(3):235-41.

29. Chu SJ, Trushkowsky RD, Paravina RD. Dental color matching instruments and systems: review of clinical and research aspects. J Dent 2010;38(Suppl 2):e2-16.

30. Chen H, Huang J, Dong X, et al. A systematic review of instrumental measurements for tooth shade matching. Quintessence Int 2012;43(8):649-59. 
31. Alsaleh S, Labban M, AlHariri M, Tashkandi E. Evaluation of self-shade matching ability of dental students using visual and instrumental means. J Dent 2012;40(Suppl 1): e82-7.

32. Paul S, Peter A, Pietrobon N, Hammerle CH. Visual and spectrophotometric shade analysis of human teeth. J Dent Res 2002;81(8):578-82.

33. Da Silva JD, Park SE, Weber HP, Ishikawa-Nagai S. Clinical performance of a newly developed spectrophotometric system on tooth color reproduction. J Prosthet Dent 2008;99(5):361-8.

34. Kim-Pusateri S, Brewer JD, Davis EL, Wee AG. Reliability and accuracy of four dental shade-matching devices. J Prosthet Dent 2009;101(3):193-9.
35. Khashayar G, Bain PA, Salari S, et al. Perceptibility and acceptability thresholds for color differences in dentistry. J Dent 2014;42(6):637-44.

36. Johnston WM, Kao EC. Assessment of appearance match by visual observation and clinical colorimetry. J Dent Res 1989;68(5):819-22.

37. Ragain Jr JC, Johnston WM. Color acceptance of direct dental restorative materials by human observers. Color Res Appl 2000;25(4):278-85.

38. Dillman DA, Smyth JD, Christian LM. Internet, phone, mail, and mixed-mode surveys: the tailored design method. $4^{\text {th }}$ ed. Hoboken, NJ: Wiley, 2014.

39. Weisberg HF, Krosnick JA, Bowen BD. An introduction to survey research, polling, and data analysis. $3^{\text {rd }}$ ed. Thousand Oaks, CA: Sage, 1996. 